\title{
Early Tracheal Extubation for Postoperative Recovery in Cardiac Surgery: Systematic Review and Meta-Analysis
}

\author{
Yi-Fan Zhao \\ Taihe Hospital \\ Zhen-Dong Huang \\ Taihe Hospital \\ Hui-Yun Gu \\ Taihe Hospital \\ Chao Zhang ( $\square$ zhangchao0803@126.com) \\ Taihe Hospital https://orcid.org/0000-0002-9891-0605 \\ Guang-Ling Guo \\ Taihe Hospital
}

\section{Research}

Keywords: Cardiac surgery, Early tracheal extubation, Coronary artery bypass, Hospital stay, Intensive care

Posted Date: July 23rd, 2020

DOI: https://doi.org/10.21203/rs.3.rs-44325/v1

License: (c) (7) This work is licensed under a Creative Commons Attribution 4.0 International License. Read Full License 


\begin{abstract}
Background: How to promote the rapid recovery of patients undergoing cardiac surgery and quality of life has been the focus of doctors' attention. To compare the safety and efficacy of early cardiac extubation with conventional extubation (late extubation) in patients undergoing cardiac surgery.
\end{abstract}

Methods: Ovid MEDLINE, Ovid Embase, EBSCOhost, Cochrane Library and ISIWeb of Science $(1946$ - November 25,2019$)$ were searched to obtain randomized controlled trials of early tracheal extubation in patients undergoing cardiac surgery.

Results: Compared with the conventional care group, in terms of effectiveness, the intensive care unit (ICU) stay and hospital length of stay in the early tracheal extubation was significantly shorter. In terms of security, most outcomes, including mortality, bleeding, stroke, acute renal failure and arrhythmia, were not statistically significant, except for myocardial infarction. However, the risk of re-intubation in the early tracheal extubation was higher than that of conventional extubation.

Conclusions: This meta-analysis confirmed that early tracheal extubation may effectively reduce ICU hospitalization time, hospital length of stay and the risk of myocardial infarction. Although early tracheal extubation does not increase the risk of safety events, the clinicians need to pay more attention to be aware of possible risk of re-intubation. Meanwhile, as a key time point for extubation within 4 hours, it may help a little to reduce the risk of re-intubation and myocardial infarction.

\title{
Introduction
}

Until now, how to promote the rapid recovery of patients undergoing cardiac surgery has been the focus of doctors' attention[1, 2]. Traditionally, cardiac surgical patients were ventilated overnight following surgery and given a regimen of high-dose opioid-based anesthesia and postoperative analgesia. Until recently, overnight ventilation has been proved to be safe[3]. But overnight ventilation tends to cost more. In the 1990s, fast-track cardiac anaesthesia (FTCA) was introduced to address the increasing demand for cardiac surgery that with limited medical functions and available resources[4].

Early tracheal extubation as a common post-cardiac care strategy was considered to be effective in improving the prognosis of cardiac surgery[3]. Studies have shown that early tracheal extubation effectively reduces ICU hospital stay and saves a lot of costs[5, 6$]$. After cardiac surgery, the traditional tracheal extubation time is usually within 8 hours $[7,8]$. Early tracheal extubation is an important part of the rapid recovery of cardiac surgery, and many clinical studies and meta-analysis had confirmed its safety[5, 7, 9-13]. Recently, guidelines concluded the early tracheal extubation time was 6 hours[14]. Moreover, extubation for more than 6 hours may lead to an increase in the incidence of pneumonia[15]. Further, study had presented that tracheal extubation time could be further shortened within 6 hours[16]. The previous meta-analysis was unable to achieve meta-analysis with a subgroup of 4 hours due to lack of evidence[12]. Mean tracheal extubation time was within 4 hours revealed by some studies[17, 18] and even tracheal extubation[18, 19] immediately after surgery[20], which bring possibility to further shorten the time of tracheal extubation using this meta-analysis to evaluate this possibility.

\section{Methods}

\section{Study eligibility criteria}

The key words, such as "cardiac surgery", "early tracheal extubation", "coronary artery bypass", "hospital stay" and "intensive care" has been used as MESH terms search trials in the following databases: Ovid MEDLINE, Ovid Embase, EBSCOhost, Cochrane Central Register of Controlled Trials, and ISIWeb of Science, the period is from 1946 to November 25, 2019. No language restrictions were applied.

\section{Identification And Selection Of Studies}

Studies were included in this systemic review and meta-analysis if they meet the following criteria: (1) Participants: patients over 18 years of age undergoing cardiac surgery; (2) Intervention: early extubation based on early extubation criteria from all original researches; (3) Comparison: normal extubation (according to the original research setting); (4) Outcomes: The primary outcomes were defined as ICU stay time and hospital stay, the secondary outcome were defined as postoperative complications, including myocardial infarction, stroke, acute renal failure, major bleeding and re-intubation; (5) Study design: Randomized controlled trial (RCT).

The following exclusion criteria were used: (1) Repeated studies; (2) High-risk craciac surgery patients judged by EuroSCORE [21]; (3) Previous coronary artery bypass graft $(C A B G)$ or valvular heart operation.

\section{Data Extraction And Quality Assessment}

The two commentators (YFZ and ZDH) first scanned the title and abstract of the relevant article independently. Based on the results, a complete article is obtained for final screening. Relevant information was independently extracted by two reviewers (YFZ and ZDH), including patients, type of surgery, extubation time, relevant outcomes, and study bias. Two reviewers independently assessed the quality of the included studies based on the criteria reported in the Cochrane's handbook [22]. All the differences in this process were solved through discussion by (CZ).

\section{Statistical analysis}


When analyzing the difference of continuous data, the mean difference (MD) with 95\% confidence interval (Cl) is used as the effect size [23]; when analyzing the difference of the binary data, the relative risk (RR) with $95 \% \mathrm{Cl}$ is used as the effect size. Heterogeneity was examined using the $\mathrm{I}^{2}$ statistic that indicates the proportion of total variability in estimates that can be attributed to heterogeneity [24]. In order to further investigation of heterogeneity from early tracheal extubation strategy, the meta-regression with early tracheal extubation group's mean extubation time as the covariable were employed. Meanwhile, the confounding factor, including the early tracheal extubation time and type of surgery, were identified as important sources of heterogeneity, and were involved in the subgroup analysis. We used the funnel plot and Egger test [25] for detecting publication bias. All statistical analyses were performed using R software.

\section{Result}

\section{Search results}

The Ovid MEDLINE, Ovid Embase, EBSCOhost, Cochrane Central Register of Controlled Trials, and ISIWeb of Science were systematically searched until April 25,2018 . The search resulted in 3,834 articles. After initial evaluation, 781 studies were removed for being duplicates, 2,267 for being irrelevant (as determined by reading the title and abstracts). Ultimately, 14 studies for reasons determined by reading the full text (Figure 1).

\section{Research characteristics and assessment of quality}

Summarizes patient characteristics (i,e, author, population, age, gender, type of surgery, and outcomes). This analysis included 14 published double-blind, parallel RCTs, 1,554 patients need heart surgery and underwent extubation. All patients met risk criteria for mild or moderate cardiac surgery by the EuroSCORE [21] used as a basis for diagnosing. All characteristics of included study are presented in Table 1. All patients were adults, primarily with regard to CABG or valve or aortic valve replacement (AVR) surgery. In all of the included studies, 9 studies $[7,9,10,17-20,26,27]$ in the experimental group were ventilated within 4 hours, and 4 studies $[5,8,28,29]$ were performed within 8 hours. The overall risks of bias in the study are shown in Table 2 .

\section{Primary outcomes}

\section{ICU length of stay}

A total of 8 studies $[5,7-9,18,27,28,30]$, involving 912 patients with a summary of data reported the length of ICU hospitalization of early tracheal extubation and conventional extubation. Compared with the conventional extubation group, the early tracheal extubation was significantly shortened for the ICU stay time $\left(\mathrm{MD}=-9.90,95 \% \mathrm{Cl}[-15.69,-4.51], \mathrm{I}^{2}=74 \%\right)$ in Figure 2.

In a subgroup analysis of extubation time (Table 3), the studies of average extubation time of less than four hours $\left(\mathrm{MD}=-17.70,95 \% \mathrm{Cl}[-35.26,-0.15], \mathrm{I}^{2}=86 \%\right)$ compared with the traditional extubation, have remarkable difference. The rest of studies' average extubation time of more than 4 hours (MD $=-6.01,95 \% \mathrm{Cl}$ $\left.[-10.6,-1.43], \mathrm{I}^{2}=55 \%\right)$ have obvious difference. In the different surgical types, the CABG group included 4 studies (MD=-5.53, 95\% CI [-9.80, -1.26$\left.], \mathrm{I}^{2}=60 \%\right)$ have significant difference; the CABG/valve group included 4 studies ( $\mathrm{MD}=-19.51,95 \% \mathrm{Cl}[36.57,-2.45], \mathrm{I}^{2}=79 \%$ ) have significant difference as well (Table 4 ). In the subgroup according to different extubation time criteria, the remarkable difference was observed in the within $8 \mathrm{~h}$ group that included 3 studies $(\mathrm{MD}=-7.00$, $95 \% \mathrm{Cl}[-7.41,-6.59], I^{2}=0 \%$; whereas the within $6 \mathrm{~h}$ group included 3 studies (MD=-3.74, 95\% Cl [-7.49, 0.01], $I^{2}=0 \%$ ) have no significant difference (Table 5 ).

\section{Hospital length of stay}

A total of 7 studies $[5,7,8,17,18,20,29]$, aggregated data from 764 patients reported results on hospital stay $\left(\mathrm{MD}=-0.63,95 \% \mathrm{Cl}[-1.22,-0.05], \mathrm{I}^{2}=65 \%\right)$ of early tracheal extubation and conventional extubation have statistical difference, compared with the conventional extubation group in Figure 3 .

In a subgroup analysis of extubation time (Table 3), the studies of the average extubation time of less than four hours, $\left(\mathrm{MD}=-0.15,95 \% \mathrm{Cl}[-0.58,0.27], I^{2}=0 \%\right)$ have no significant difference compared with the traditional extubation. Instead, the rest of studies that the average extubation time is more than 4 hours $\left(\mathrm{MD}=-1.1,95 \% \mathrm{Cl}[-1.38,-0.83], \mathrm{I}^{2}=0 \%\right)$ have significant difference. In the different surgical types, the CABG group showed no obvious difference among these 6 studies (MD=-0.58, 95\% Cl [-1.22, 0.07], $\mathrm{I}^{2}=71 \%$ ); the CABG/AVR group included 1 study (MD=-1.1, 95\% Cl $\left.[-2.62,0.42], \mathrm{I}^{2}=\mathrm{NA}\right)$ and no significant difference was found (Table 4). In the subgroup according to different extubation time criteria, the group within $8 \mathrm{~h}$ included 2 studies $\left(\mathrm{MD}=-0.57,95 \% \mathrm{Cl}[-1.65,0.51], \mathrm{I}^{2}=93 \%\right)$ and no significant difference had shown. On the contrary, the group within $6 \mathrm{~h}$ involved 1 study $\left(\mathrm{MD}=-1.20,95 \% \mathrm{Cl}[-2.38,-0.02], \mathrm{I}^{2}=\mathrm{NA}\right)$ have significant difference; the group within $4 \mathrm{~h}\left(\mathrm{MD}=-0.87,95 \% \mathrm{Cl}[-2.07,0.32], \mathrm{I}^{2}=0 \%\right)$ have no remarkable difference in both 2 studies (Table 5).

\section{Secondary outcomes}

\section{Mortality}

There is no striking difference on the risk of death ( $\left.\mathrm{RR}=0.87,95 \% \mathrm{Cl}[0.51,1.49], \mathrm{I}^{2}=0 \%\right)$ reported by a total of 1262 patients in 8 studies $[5,7,8,18-20,29,30]$. The risk of death of early was $3.3 \%$ in tracheal extubation group that is the same with the conventional extubation group. The researchers of this paper divided

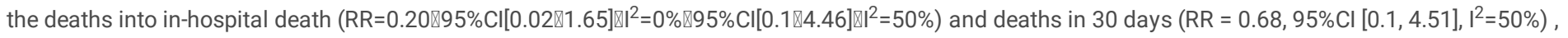
and that both of the two outcomes have no significant difference in Figure 4.

In a subgroup analysis of extubation time (Table 3), no significant difference was illustrated by the studies that the average extubation time is less than four hours $\left(\mathrm{RR}=0.69,95 \% \mathrm{Cl}[0.19,2.53], \mathrm{I}^{2}=0 \%\right)$ compared with the traditional extubation. Likewise, the rest of studies' average extubation time of more than 4 hours (RR=0.91, 95\% $\mathrm{Cl}[0.51,1.65], \mathrm{I}^{2}=37 \%$ ) have no obvious difference. In the different surgical types, the CABG group included 5 studies (RR=0.36, $95 \% \mathrm{Cl}$ $[0.11,1.15], I^{2}=0 \%$ ) and no significant difference was demonstrated; the valve group included one study, and it reported zero mortality; the CABG/AVR group 
included 1 study without death; the CABG/valve group only involved 1 study (RR=1, 95\% Cl [0.02, 49.06], $\left.\mathrm{I}^{2}=\mathrm{NA}\right)$ and no significant difference was reported (Table 4). In the subgroup according to different extubation time criteria, the group within $8 \mathrm{~h}$ included 2 studies (RR=0.32, 95\% $\left.\mathrm{Cl}[0.03,3.05], \mathrm{I}^{2}=0 \%\right)$ have no significant difference; the group within $6 \mathrm{~h}$ included 2 studies (RR=0.48,95\% $\mathrm{Cl}[0.04,5.94], \mathrm{I}^{2}=69 \%$ ) and no significant difference between studies; the group within $4 \mathrm{~h}$ included 1 study, which reported zero mortality (Table 5).

\section{Postoperative complications}

\section{Re-intubation}

A total of 1,107 patients in 10 studies[5, 8, 9, 17-20, 28-30] recorded the number of patients requiring re-intubation. Compared with the conventional extubation grou, the risk of re-intubation in the early tracheal extubation group $\left(\mathrm{RR}=2.14,95 \% \mathrm{Cl}[1.04,4.38], \mathrm{I}^{2}=0 \%\right)$, have striking difference.

In a subgroup analysis of extubation time (Table 3), the average extubation time of 5 studies is less than 4 hours $\left(\mathrm{RR}=1.38,95 \% \mathrm{Cl}[0.48,4.00], \mathrm{I}^{2}=0 \%\right)$, and no statistical difference was illustrated. The rest studies that the average extubation time is more than 4 hours $\left(\mathrm{RR}=3.03,95 \% \mathrm{Cl}[1.11,8.29], \mathrm{I}^{2}=0 \%\right)$ have significant difference. In the different surgical types, the CABG group included 7 studies ( $R R=2.12,95 \% \mathrm{Cl}[0.66,6.83], \mathrm{I}^{2}=0 \%$ ) and the CABG/valve group included 2 studies $\left(\mathrm{RR}=3.63,95 \% \mathrm{Cl}[1.00,13.14], \mathrm{I}^{2}=0 \%\right)$, have striking difference; the valve group included 1 study $\left(\mathrm{RR}=1,95 \% \mathrm{Cl}[0.22,4.63], \mathrm{I}^{2}=\mathrm{NA}\right)$ and no significant difference was shown (Table 4). In the subgroup according to different extubation time criteria, the within $8 \mathrm{~h}$ group included 2 studies (RR=2.13, $95 \% \mathrm{Cl}[0.20,22.36], \mathrm{I}^{2}=0 \%$ ) have no significant difference; the group within $6 \mathrm{~h}$ included 3 studies $\left(\mathrm{RR}=3.20,95 \% \mathrm{Cl}[0.96,10.66], \mathrm{I}^{2}=0 \%\right)$ and no significant difference was represented; the group within 4 h included 1 study ( $\left.R R=2.84,95 \% \mathrm{Cl}[0.12,65.12], I^{2}=\mathrm{NA}\right)$ and no significant difference was shown (Table 5 ).

\section{Myocardial infarction}

A total of 1127 patients in 9 studies $[5,7-9,19,20,27,29,30]$ recorded the number of patients with postoperative myocardial infarction, and 3 of them reported no patients with myocardial infarction. The risk of myocardial infarction was $1.6 \%$ in the early tracheal extubation group and $4.3 \%$ in the conventional extubation group. The risk of early extubation was lower than that of conventional extubation $\left(\mathrm{RR}=0.43,95 \% \mathrm{Cl}[0.23,0.79], \mathrm{I}^{2}=0 \%\right)$, and the difference was statistically significant.

In a subgroup analysis of extubation time (Table 3), the average extubation time of the 6 studies was within 4 hours $\left(\mathrm{RR}=0.34,95 \% \mathrm{Cl}[0.15,0.76], \mathrm{I}^{2}=0 \%\right)$ and there were significant differences. The average extubation time of the rest studies is more than 4 hours $\left(\mathrm{RR}=0.61,95 \% \mathrm{Cl}[0.22,1.65], \mathrm{I}^{2}=4 \%\right)$, which have significant difference. In the different surgical types, the CABG group included 6 studies (RR=0.43, 95\% $\mathrm{Cl}[0.16,1.18], \mathrm{I}^{2}=0 \%$ ) and no significant difference was shown; the CABG/valve group included 2 studies (RR=0.4, 95\% $\mathrm{Cl}[0.06,2.53], \mathrm{I}^{2}=74 \%$ ) and no significant difference was shown; the valve group included 1 study, the study reported zero incidence (Table 4). In the subgroup according to different extubation time criteria, the group within $8 \mathrm{~h}$ included 3 studies $\left(\mathrm{RR}=0.55,95 \% \mathrm{Cl}[0.15,1.99], \mathrm{I}^{2}=0 \%\right)$ and no significant difference was stated; the group within $6 \mathrm{~h}$ included 2 studies $\left(\mathrm{RR}=0.49,95 \% \mathrm{Cl}[0.06,4.10], \mathrm{I}^{2}=51 \%\right)$ and no significant difference was shown (Table 5).

\section{Bleeding}

A total of 684 patients in 8 studies $[5,7,9,17,19,20,28]$ recorded major bleeding after surgery. The risk of major bleeding in the early tracheal extubation group was $11.2 \%$, and the conventional care group is $9.8 \%$. The risk of major bleeding in the early group was slightly higher than that in the conventional group. The difference between the two groups $\left(\mathrm{RR}=0.94,95 \% \mathrm{Cl}[0.67,1.32], \mathrm{I}^{2}=0 \%\right)$ have no obvious difference.

In a subgroup analysis of extubation time (Table 3), the average extubation time of the 5 studies is less than 4 hours $\left(\mathrm{RR}=1.06,95 \% \mathrm{Cl}[0.75,1.50], \mathrm{I}^{2}=0 \%\right)$ and no significant difference was shown. The average extubation time of the rest studies is more than 4 hours $\left(\mathrm{RR}=0.58,95 \% \mathrm{Cl}[0.21,1.62], \mathrm{I}^{2}=0 \%\right)$ and no significant difference was shown. In the different surgical types, the CABG group included 6 studies (RR=0.83, 95\% $\left.\mathrm{Cl}[0.37,1.90], \mathrm{I}^{2}=0 \%\right)$ and no significant difference was shown; the $C A B G /$ valve group included 2 studies ( $R R=2.74,95 \% \mathrm{Cl}[0.05,152.22], \mathrm{I}^{2}=73 \%$ ) and no significant difference was shown; the valve group included 1 study (RR=1.03,95\% $\left.\mathrm{Cl}[0.74,1.43], \mathrm{I}^{2}=\mathrm{NA}\right)$ and no significant difference was shown (Table 4). In the subgroup according to different extubation time criteria, the group within $8 \mathrm{~h}$ included 3 studies ( $\mathrm{RR}=0.87,95 \% \mathrm{Cl}[0.31,2.44], \mathrm{I}^{2}=0 \%$ ) and no significant difference was shown; the group within $6 \mathrm{~h}$ included 1 study $\left(\mathrm{RR}=0.50,95 \% \mathrm{Cl}[0.05,5.37], \mathrm{I}^{2}=\mathrm{NA}\right)$ and no significant difference was shown; the group within $4 \mathrm{~h}$ included $1 \mathrm{study}(\mathrm{RR}=0.94,95 \% \mathrm{Cl}[0.06$, 13.93], $I^{2}=\mathrm{NA}$ ) and no significant difference was represented (Table 5).

\section{Stroke}

A total of 750 patients in 7 studies $[5,8,9,20,21,28,30]$ recorded postoperative stroke, and there are no stroke patients in the three studies. The risk of stroke in the early tracheal extubation group was $0.02 \%$, and that in the routine care group was $1.5 \%$. After comparison between the two groups $(\mathrm{RR}=0.52,95 \% \mathrm{Cl}$ $\left.[0.17,1.56], I^{2}=0 \%\right)$, there was no significant difference.

In a subgroup analysis of extubation time (Table 3 ), average extubation time of less than 4 hours by 3 of the studies (RR=0.67, $\left.95 \% \mathrm{Cl}[0.09,4.90], \mathrm{I}^{2}=0 \%\right)$ have no significant difference. The average extubation time of the rest studies is more than 4 hours $\left(\mathrm{RR}=0.47,95 \% \mathrm{Cl}[0.12,1.75], I^{2}=0 \%\right)$ and no significant difference was shown. In the different surgical types, the CABG group included 5 studies (RR=0.48, 95\% $\mathrm{Cl}[0.11,2.10], \mathrm{I}^{2}=0 \%$ ) and no significant difference was shown; the CABG/valve group included 2 studies (RR=0.57, 95\% $\mathrm{Cl}[0.11,2.99], \mathrm{I}^{2}=0 \%$ ) and no significant difference was shown (Table 4). In the subgroup according to different extubation time criteria, the group within $8 \mathrm{~h}$ included 3 studies (RR=0.65, 95\% $\mathrm{Cl}[0.09,4.81], \mathrm{I}^{2}=0 \%$ ) and no significant difference was shown; the group within $6 \mathrm{~h}$ included 2 studies ( $\left.\mathrm{RR}=0.56,95 \% \mathrm{Cl}[0.11,2.94], \mathrm{I}^{2}=0 \%\right)$ and no significant difference was presented (Table 5$)$. 


\section{Acute renal failure}

A total of 597 patients in 5 studies $[8,20,21,27,28]$ recorded acute renal failure after surgery, and no patients with renal failure are shown in either study. The risk of severe acute renal failure in the early group was $1.1 \%$, which was similar to the conventional care group ( $0.9 \%)$. Statistical differences between the two groups $\left(\mathrm{RR}=1.06,95 \% \mathrm{Cl}[0.33,3.41], \mathrm{I}^{2}=0 \%\right)$ have no striking difference.

In a subgroup analysis of extubation time (Table 3), average extubation time of less than 4 hours by 2 of the studies $\left(\mathrm{RR}=1.53,95 \% \mathrm{Cl}[0.27,8.72], \mathrm{I}^{2}=0 \%\right)$ have no significant difference. The average extubation time of rest studies is more than 4 hours $\left(\mathrm{RR}=0.78,95 \% \mathrm{Cl}[0.16,3.92], \mathrm{I}^{2}=0 \%\right)$ and no significant difference was shown. In the different surgical types, the CABG group included 2 studies, which reported that the incidence of acute renal failure is zero; the CABG/valve group included 3 studies ( $R R=1.06,95 \% \mathrm{Cl}[0.29,3.85], \mathrm{I}^{2}=0 \%$ ) and have no striking difference (Table 4$)$. In the subgroup according to different extubation time criteria, the group within $8 \mathrm{~h}$ included 1 study and reported no Acute renal failure; the group within $6 \mathrm{~h}$ included $1 \mathrm{study}\left(\mathrm{RR}=0.42,95 \% \mathrm{Cl}[0.02,10.11], \mathrm{I}^{2}=0 \%\right)$ and no significant difference was shown (Table 5).

\section{Arrhythmia}

A total of 6 studies $[5,8,19,20,29,30]$, and a total of 750 patients got postoperative arrhythmias, and no arrhythmia patients was reported in one of the studies. The risk of arrhythmia was $16.6 \%$ in the early tracheal extubation group and $18.3 \%$ in the conventional extubation group. The statistical difference between the early tracheal extubation group and the conventional extubation group (RR=1.25, 95\% $\left.\mathrm{Cl}[0.93,1.68], \mathrm{I}^{2}=5 \%\right)$ have no conspicuous difference.

In a subgroup analysis of extubation time (Table 3), no significant difference was shown in 3 hours (RR=1.02, 95\% Cl [0.70, 1.51], $\left.\left.\right|^{2}=0 \%\right)$ of the study time with average extubation time less than 4 hours. The rest of studies' average extubation time of more than 4 hours $\left(\mathrm{RR}=1.61,95 \% \mathrm{Cl}[1.01,2.57], \mathrm{I}^{2}=35 \%\right)$ have shown conspicuous difference. In the different surgical types, the CABG group included 4 studies (RR=0.97, 95\% $\left.\mathrm{Cl}[0.65,1.46], \mathrm{I}^{2}=0 \%\right)$ and have no significant difference; the CABG/valve group included 1 study ( $\left.R R=2.3,95 \% \mathrm{Cl}[1.23,4.33], I^{2}=\mathrm{NA}\right)$ and significant difference was presented; the valve group included 1 study $\left(\mathrm{RR}=1.17,95 \% \mathrm{Cl}[0.63,2.16], \mathrm{I}^{2}=\mathrm{NA}\right)$ and have no significant difference (Table 4). In the subgroup according to different extubation time criteria, the group within $8 \mathrm{~h}$ included 1 study (RR=0.89, $\left.95 \% \mathrm{Cl}[0.36,2.17], \mathrm{I}^{2}=0 \%\right)$ and no significant difference was illustrated; the group within $6 \mathrm{~h}$ included $2 \mathrm{studies}$ (RR=2.03, 95\% Cl $\left.[1.16,3.56], \mathrm{I}^{2}=0 \%\right)$ and have no significant difference (Table 5).

\section{Meta-regression}

The meta-regression results are presented below, the incidence of bleeding $(\beta=-0.07, P=0.42,95 \% C l[-0.25,0.11])$, acute renal failure $(\beta=-0.14, P=0.45$, $95 \% \mathrm{Cl}[-0.53,0.24])$, hospital stay $(\beta=-0.16, P=0.003,95 \% \mathrm{Cl}[-0.26,-0.05])$, death $(\beta=0.22, P=0.10,95 \% \mathrm{Cl}[-0.04,0.49]), \mathrm{ICU}$ length of stay $(\beta=1.11, P=0.39,95 \% \mathrm{Cl}$ $[-1.41,3.64])$, stroke $(\beta=0.18, P=0.48,95 \% \mathrm{Cl}[-0.31,0.67])$, re-intubation $(\beta=0.12, P=0.25,95 \% \mathrm{Cl}[-0.08,0.32])$, myocardial infarction $(\beta=0.15, P=0.11,95 \% \mathrm{Cl}$ $[-0.03,0.32])$, arrhythmia $(\beta=0.1, P=0.19,95 \% \mathrm{Cl}[-0.05,0.26])$.

\section{Publication bias}

The publication bias of five outcomes, including ICU length of stay [t=-0.86, $p=0.43]$, hospital length of stay [t=0.89, $p=0.41]$, re-intubation [t=0.68, $p=0.53$ ], bleeding $[p=0.47, t=0.83]$, myocardial infarction [ $t=-0.44, p=0.68]$, and arrhythmia [t=0.83, $p=0.47]$, weren't detected.

\section{Discussion}

In this meta-analysis, in terms of effectiveness, early tracheal extubation can significantly reduce the length of stay in ICU and slightly reduced the average hospital stays. As for security, compared with previous meta-analysis[11, 13], the risk of re-intubation in the early extubation group is significantly higher than in the conventional extubation group. Seven of the ten studies reporting re-intubation risk reported a higher risk of extubation than the conventional extubation group. However, the risk of myocardial infarction in the early extubation group was lower than that in the conventional extubation group. The researchers of this paper also compared deaths from tracheal extubation at different period, and it found that there were no significant differences between hospital deaths in both tracheal extubation and deaths within 30 days after discharge. Moreover, in all deaths, no significant difference was shown in the risk of both tracheal extubation, including deaths in the hospital and death within 30 days after discharge.

In the subgroup based on the different types of cardiac surgery, the results have shown that the risk of re-intubation and arrhythmia in the CABG/valve group was higher than that in the other groups. Nevertheless, the ICU hospital stays in this group was significantly shorter than other types of surgery, and the heterogeneity was higher. Even though early tracheal extubation might be more effective in reducing the cost of medical care for patients requiring valve surgery, there might be a greater risk of medical safety for the patients.

The researchers of this paper investigated the feasibility of extubation 4 hours after cardiac surgery. The average time of early tracheal extubation within 4 hours was better than that of more than 4 hours in the three outcomes of the ICU length of stay, re-intubation and myocardial infarction. The ICU length of stay shortened the incidence of $M D=10.69$, myocardial infarction and decreased the incidence of $R R=0.21$. Although the reduction in the risk of reintubation is not statistically significant, the significant increase in the risk of reintubation in the group over $4 \mathrm{~h}$ is of significant statistical importance, which indicates that further shortening the extubation time may lead to a reduction in risk, perhaps the use of auxiliary schemes to assist related extubation decisions in the future can shorten the time and maintain safety[31]. Whereas, the increase in complications within mean 4-hour tracheal extubation were mainly manifested in bleeding and acute renal failure. However, neither of the two results was statistically significant. 
Currently, of the fourteen studies included, nine of them had an average extubation time within 4 hours of surgery. Four studies[9, 18, 19, 27] have demonstrated the feasibility of average extubation time within 2 hours, and two studies[18, 19] had few reports of complication outcomes. Salah et al.[27] reported a significantly increase in the risk of bleeding. In the studies of immediate extubation, early tracheal extubation was undoubtedly reduced hospital stay, but there were few reports on safety. Study have shown that ultra-rapid (1-2 h) extubation can also reduce the hospitalization time and cost of ICU, and will not increase related complications[32]. There were no descriptions ways to prevent major bleeding in 14 studies, but studies have shown [33] that interventions such as thromboembolic diagnosis and treatment in blunt patients can effectively reduce the risk of major bleeding in patients with early tracheal extubation.

Many studies have set the time standard for early extubation. If the ventilation time of patients exceeds this standard, it will be excluded from the early extubation group. The researchers of this paper hope to determine the most effective time standard by comparing different standards. Of the 14 included articles, five studies did not set the standard time for early extubation[19, 20, 27-29]. Four studies set the maximum time limit for early extubation to 8 hours[7-10], and three studies set the maximum time limit for early extubation to 6 hours[5, 18,30], the standards of the remaining two studies are all within 4 hours $[17,26]$. Except for studies based on the 8-hour criterion that have proven the benefits in reducing hospital stays, almost all results are not statistically significant. Therefore, the researchers of this paper are not sure when the extubation time standard is beneficial to the effect of early extubation.

Our meta-regression analysis illuminated that the risk of bleeding, acute renal failure and routine hospital stay were negatively correlated with early tracheal extubation time, and the remaining six results were positively correlated with early tracheal extubation time. It indicates that shortening of extubation time is more beneficial.

Finally, the effects on quality of overall cost effectiveness need to be clarified in future studies. If the length of stay in ICU and hospitals is significantly reduced, rapid treatment for cardiac surgery patients is likely to be cost-effective. Studies[34, 35] believe that early extubation can effectively reduce total hospital cost. Lu et al.[36] believe the early extubation intervention was associated with a reduction in departmental cost savings in uncomplicated CABG surgery. This meta-analysis of early tracheal extubation in cardiac surgery only appropriately applied in the efficacy and safety of early tracheal extubation rather than FTCA, and is more accurate than the previous article, which pointed out risk of complications that not indicated by previous meta-analysis. Provided an newest idea to further shorten the time of extubation and a comprehensive reference for the safety of early tracheal extubation strategies in patients with different cardiac operations.

\section{Limitations}

Firstly, the early tracheal extubation strategy is difficult to implement the blinding, this may affect the quality of our research. At the same time, the lack of data in some studies may lead to some controversy over the effectiveness of the results. Secondly, different studies used different anesthesia criteria, high doses of anesthesia require longer ventilation support, remifentanil has faster recovery and less respiratory depression, and there are also ways to speed up recovery after discharge. This is a confounding factor that we have difficulty assessing. Thirdly, due to the insufficient number of studies, the validity and veracity of subgroup analysis, meta-regression and publication bias may be affected.

\section{Conclusion}

Early tracheal extubation may effectively reduce ICU hospitalization time, hospital length of stay and the risk of myocardial infarction. Although early tracheal extubation does not increase the risk of safety events, the clinicians need to pay more attention to be aware of possible risk of re-intubation, and it is not recommended for coronary artery bypass graft or valve. Meanwhile, as a key time point for extubation within 4 hours, it may help a little to reduce the risk of re-intubation and myocardial infarction. Based on sample size limitations, the conclusions of this study need to be verified by large sample clinical studies.

\section{Abbreviations}

AVR

Aortic valve replacement, CABG:Coronary artery bypass grafting, Cl:Confidence interval, FTCA:fast-track cardiac anaesthesia, ICU:Intensive care unit, MD:Mean difference, NA:Not available, RCT:Randomized controlled trial, RR:Relative risk.

\section{Declarations}

Ethics approval and consent to participate: Not applicable.

Consent for publication: Not applicable.

Availability of data and materials: Not applicable.

Competing interests: All authors declare that they have no competing interests.

Funding: Not applicable.

Authors' contributions: CZ and GLG had full access to all of the data in the study, and took responsibility for the integrity of the data and the accuracy of the data analysis. YFZ, ZDH and HYG designed the study. ZDH and YFZ developed and tested the data collection forms. YFZ and ZDH acquired the data. YFZ and ZDH conducted the analysis and interpreted the data. YFZ and ZDH drafted the manuscript. All authors critically revised the manuscript. CZ and GLG had guarantor. 


\section{References}

1. Miller D, Lewis SR, Pritchard MW, et al. Intravenous versus inhalational maintenance of anaesthesia for postoperative cognitive outcomes in elderly people undergoing non-cardiac surgery. Cochrane Database of Systematic Reviews. 2018;8:CD012317.

2. Macaire $\mathrm{P}, \mathrm{Ho} \mathrm{N}$, Nguyen T, et al. Ultrasound-guided continuous thoracic erector spinae plane block within an enhanced recovery program is associated with decreased opioid consumption and improved patient postoperative rehabilitation after open cardiac surgery-a patient-matched, controlled beforeand-after study. J Cardiothorac Vasc Anesth. 2019;33(6):1659-67.

3. Krebs ED, Hawkins RB, Mehaffey JH, et al. Is routine extubation overnight safe in cardiac surgery patients? J Thorac Cardiovasc Surg. 2019;157(4): 1533-42 e2.

4. Cheng DC. Fast-track cardiac surgery: economic implications in postoperative care. J Cardiothorac Vasc Anesth. 1998;12(1):72-9.

5. Cheng D, Karski J, Peniston C, et al. Early tracheal extubation after coronary artery bypass graft surgery reduces costs and improves resource use. A prospective, randomized, controlled trial. Anesthesiology. 1996;85(6):1300-10.

6. Ovroutski S, Kramer P, Nordmeyer S, et al. Early extubation is associated with improved early outcome after extracardiac total cavopulmonary connection independently of duration of cardiopulmonary bypass. Eur J Cardiothorac Surg. 2018;54(5):953-8.

7. Berry P, Thomas S, Mahon S, et al. Myocardial ischaemia after coronary artery bypass grafting: early vs late extubation. Br J Anaesth. 1998;80(1):20-5.

8. Michalopoulos A, Nikolaides A, Antzaka C, et al. Change in anaesthesia practice and postoperative sedation shortens ICU and hospital length of stay following coronary artery bypass surgery. Respir Med. 1998;92(8):1066-70.

9. Quasha AL, Loeber N, Feeley TW, et al. Postoperative respiratory care: a controlled trial of early and late extubation following coronary-artery bypass grafting. Anesthesiology. 1980;52(2):135-41.

10. Dumas A, Dupuis $\mathrm{GH}$, Searle N, et al. Early versus late extubation after coronary artery bypass grafting: effects on cognitive function. J Cardiothorac Vasc Anesth. 1999;13(2):130-5.

11. Zhu F, Gomersall CD, Ng SK, et al. A randomized controlled trial of adaptive support ventilation mode to wean patients after fast-track cardiac valvular surgery. Anesthesiology. 2015;122(4):832-40.

12. Hawkes CA, Dhileepan S, Foxcroft D. Early extubation for adult cardiac surgical patients. Cochrane Database Syst Rev. 2003;undefined(4):CD003587.

13. Wong WT, Lai VK, Chee YE, et al. Fast-track cardiac care for adult cardiac surgical patients. Cochrane Database Syst Rev. 2016;9(undefined):CD003587.

14. Engelman DT, Ben Ali W, Williams JB, et al. Guidelines for perioperative care in cardiac surgery: enhanced recovery after surgery society recommendations. JAMA Surg. 2019.

15. ER RVU, EA BR. BB, et al. Risk factors for the development of postoperative pneumonia after cardiac surgery. Archivos de cardiologia de Mexico. 2016;86(3):203-7.

16. Grocott HP. Early extubation after cardiac surgery: The evolution continues. J Thorac Cardiovasc Surg. 2017;154(5):1654-5.

17. Nicholson D, Kowalski S, Hamilton G, et al. Postoperative pulmonary function in coronary artery bypass graft surgery patients undergoing early tracheal extubation: a comparison between short-term mechanical ventilation and early extubation. J Cardiothorac Vasc Anesth. 2002;16(1):27-31.

18. Nougarède B, Caillet C, Bizouarn P, et al. Impact of propofol and sufentanil target controlled infusion with monitoring of bispectral index on drugs and medical device costs in operating room and intensive care unit, for routine cardiac surgery with cardiopulmonary bypass. Journal de Pharmacie Clinique. 2004;23(219- 26 .

19. Gangopadhyay S, Acharjee A, Nayak S, et al. Immediate extubation versus standard postoperative ventilation: Our experience in on pump open heart surgery. Indian journal of anaesthesia. 2010;54(6):525-30.

20. Silbert B, Santamaria J, O'Brien J, et al. Early extubation following coronary artery bypass surgery: a prospective randomized controlled trial. The Fast Track Cardiac Care Team Chest. 1998;113(6):1481-8.

21. Roques F, Nashef SA, Michel P, et al. Risk factors and outcome in European cardiac surgery: analysis of the EuroSCORE multinational database of 19030 patients. Eur J Cardiothorac Surg. 1999;15(6): 816 - 22; discussion 22 - 3.

22. Cumpston M, Li T, Page MJ, et al. Updated guidance for trusted systematic reviews: a new edition of the Cochrane Handbook for Systematic Reviews of Interventions. Cochrane Database Syst Rev. 2019;10:ED000142.

23. Bakbergenuly I, Hoaglin DC, Kulinskaya E. Estimation in meta-analyses of mean difference and standardized mean difference. Stat Med. 2019;39(2):17191.

24. Lin L. Comparison of four heterogeneity measures for meta-analysis. J Eval Clin Pract. 2020;26(1):376-84.

25. Lin L, Chu H. Quantifying publication bias in meta-analysis. Biometrics. 2018;74(3):785-94.

26. Pettersson P, Settergren G, Owall A. Similar pain scores after early and late extubation in heart surgery with cardiopulmonary bypass. J Cardiothorac Vasc Anesth. 2004;18(1):64-7.

27. Salah M, Hosny $\mathrm{H}$, Salah M, et al. Impact of immediate versus delayed tracheal extubation on length of ICU stay of cardiac surgical patients, a randomized trial. Heart lung vessels. 2015;7(4):311-9.

28. Simeone F, Biagioli B, Scolletta S, et al. Optimization of mechanical ventilation support following cardiac surgery. J Cardiovasc Surg (Torino). 2002;43(5):633-41. 
29. Reis J, Mota JC, Ponce P, et al. Early extubation does not increase complication rates after coronary artery bypass graft surgery with cardiopulmonary bypass. Eur J Cardiothorac Surg. 2002;21(6):1026-30.

30. Reyes A, Vega G, Blancas R, et al. Early vs conventional extubation after cardiac surgery with cardiopulmonary bypass. Chest. 1997;112(1):193-201.

31. Kang H, Zhang ZW, Pu HQ, et al. The correlation of fast-track extubation ultrasound score and clinical multi-organ information indicators of postoperative of cardiac surgery. Sichuan Da Xue Xue Bao Yi Xue Ban. 2019;50(6):808-14.

32. Kim KM, Kwak JG, Shin BC, et al. Early experiences with ultra-fast-track extubation after surgery for congenital heart disease at a single center. Korean J Thorac Cardiovasc Surg. 2018;51(4):247-53.

33. Ranucci M, Baryshnikova E, Pistuddi V, et al. The effectiveness of 10 years of interventions to control postoperative bleeding in adult cardiac surgery. Interact CardioVasc Thorac Surg. 2016;24(2):ivw339.

34. Badhwar V, Esper S, Brooks M, et al. Extubating in the operating room after adult cardiac surgery safely improves outcomes and lowers costs. The Journal of Thoracic Cardiovascular Surgery. 2014;148(6):3101-9.e1.

35. Marcantuono R, Gutsche J, Burke-Julien M, et al. Rationale, development, implementation, and initial results of a fast track protocol for transfemoral transcatheter aortic valve replacement (TAVR). Catheterization cardiovascular interventions: official journal of the Society for Cardiac Angiography Interventions. 2015;85(4):648-54.

36. Lu SY, Lai Y, Dalia AA. Implementing a cardiac enhanced recovery after surgery protocol: nuts and bolts. Journal of Cardiothoracic and Vascular Anesthesia. 2019.

\section{Tables}

Table 1 Characteristics of included studies 


\begin{tabular}{|c|c|c|c|c|c|c|c|c|}
\hline \multirow[t]{2}{*}{ Study } & \multirow[t]{2}{*}{ Year } & \multirow[t]{2}{*}{ Surgery } & \multirow[t]{2}{*}{$N(E / L)$} & \multirow[t]{2}{*}{ Age (E/L) } & \multicolumn{2}{|l|}{ Men, No (\%) } & \multirow{2}{*}{$\begin{array}{l}\text { Extubation time } \\
\text { (hrs) (E/L) }\end{array}$} & \multirow[t]{2}{*}{ Outcomes } \\
\hline & & & & & $\mathbf{E}$ & $\mathrm{L}$ & & \\
\hline \multirow[t]{2}{*}{ Berry ${ }^{7}$} & \multirow[t]{2}{*}{1998} & \multirow[t]{2}{*}{ CABG } & \multirow[t]{2}{*}{$43 / 42$} & $58.4(38-70) /$ & \multirow[t]{2}{*}{$35(81.4 \%)$} & \multirow[t]{2}{*}{$39(92 . .9 \%)$} & & \multirow{2}{*}{$\begin{array}{l}\text { ICU stay, Hospital stay, } \\
\text { Mortality, MI, Bleeding }\end{array}$} \\
\hline & & & & $61.1(44-70)$ & & & $12.62(3.09)$ & \\
\hline \multirow[t]{2}{*}{ Cheng $^{5}$} & \multirow[t]{2}{*}{1996} & \multirow[t]{2}{*}{ CABG } & \multirow[t]{2}{*}{$60 / 60$} & $59.3(8.8) /$ & \multirow[t]{2}{*}{ NA } & \multirow[t]{2}{*}{ NA } & $4.1(1.1) /$ & \multirow{2}{*}{$\begin{array}{l}\text { ICU stay, Hospital stay, } \\
\text { Mortality, MI, stroke, } \\
\text { Acute renal failure, } \\
\text { Bleeding, Reintubation, } \\
\text { Arrhythmia }\end{array}$} \\
\hline & & & & $61.2(8.7)$ & & & $18.9(1.4)$ & \\
\hline \multirow[t]{2}{*}{ Dumas $^{10}$} & \multirow[t]{2}{*}{1999} & \multirow[t]{2}{*}{ CABG } & \multirow[t]{2}{*}{$22 / 25$} & $56.4(8.9) /$ & \multirow[t]{2}{*}{$16(72.7 \%)$} & \multirow[t]{2}{*}{$20(80.0 \%)$} & $3.5(2.2) /$ & \multirow[t]{2}{*}{ Stroke } \\
\hline & & & & $62.7(8.5)$ & & & $10.3(1.8)$ & \\
\hline Michalopoulos ${ }^{8}$ & 1998 & CABG & $72 / 72$ & $58.9(7.6) / 60.2(8.3)$ & $67(93.1 \%)$ & $66(91.7 \%)$ & $\begin{array}{l}7.3(0.7) / 11.6 \\
(1.3)\end{array}$ & $\begin{array}{l}\text { ICU stay, Hospital stay, } \\
\text { Mortality, MI, stroke, } \\
\text { Acute renal failure, } \\
\text { Bleeding, Reintubation, } \\
\text { Arrhythmia }\end{array}$ \\
\hline Nicholson $^{17}$ & 2002 & CABG & $18 / 17$ & $62.1(10.8) / 58.8(6.9)$ & $16(88.9 \%)$ & $16(94.1 \%)$ & $\begin{array}{l}0.76(0.46) / 3.36 \\
(0.35)\end{array}$ & Bleeding, Reintubation \\
\hline Nougarede $^{18}$ & 2004 & $\begin{array}{l}\text { CABG or } \\
\text { valve }\end{array}$ & NA & NA & NA & NA & $0(0) / 6.2(4.88)$ & ICU stay, reintubation \\
\hline Pettersson 26 & 2004 & CABG/AVR & $30 / 27$ & $64(10) / 64(11)$ & $25(83.3 \%)$ & $21(77.8 \%)$ & $\begin{array}{l}3.3(1.7) / 6.7 \\
(1.4)\end{array}$ & Hospital stay, Mortality \\
\hline Quasha9 $^{9}$ & 1980 & CABG & $16 / 20$ & $56(9) / 60(9)$ & NA & NA & $2(2) / 18(3)$ & $\begin{array}{l}\text { ICU stay, Stroke, MI, } \\
\text { Bleeding, Reintubation }\end{array}$ \\
\hline Salah $^{27}$ & 2015 & $\begin{array}{l}\text { CABG or } \\
\text { valve }\end{array}$ & $26 / 26$ & $\begin{array}{l}43.81(13.12) / 48.69 \\
(12.53)\end{array}$ & $15(57.7 \%)$ & $25(86.2 \%)$ & $\begin{array}{l}0.23 \\
(1.18) / 12.94 \\
(5.03)\end{array}$ & $\begin{array}{l}\text { ICU stay, MI, Acute renal } \\
\text { failure, Bleeding }\end{array}$ \\
\hline Silbert $^{20}$ & 1998 & CABG & $38 / 42$ & $62(7) / 62(8)$ & $30(78.9 \%)$ & $32(76.2 \%)$ & $4(3.75) / 7(4.23)$ & $\begin{array}{l}\text { Hospital stay, Mortality, } \\
\text { MI, Reintubation, } \\
\text { Arrhythmia }\end{array}$ \\
\hline Simeone ${ }^{28}$ & 2002 & $\begin{array}{l}\text { CABG or } \\
\text { valve }\end{array}$ & $24 / 25$ & $63.3(8.2) / 67.5(7.1)$ & $20(83.3 \%)$ & $20(80.0 \%)$ & $\begin{array}{l}6.5(3.8) / 8.6 \\
(3.5)\end{array}$ & $\begin{array}{l}\text { ICU stay, stroke, Acute } \\
\text { renal failure, Bleeding, } \\
\text { Reintubation }\end{array}$ \\
\hline Reyes $^{30}$ & 1997 & $\begin{array}{l}\text { CABG or } \\
\text { valve }\end{array}$ & $201 / 203$ & $61(10.7) / 61(11.3)$ & $137(68.2 \%)$ & $136(67.0 \%)$ & $\begin{array}{l}10(169.5) / 21 \\
(308)\end{array}$ & $\begin{array}{l}\text { ICU stay, Mortality, MI, } \\
\text { stroke, Acute renal } \\
\text { failure, Reintubation, } \\
\text { Arrhythmia }\end{array}$ \\
\hline Gangopadhyay ${ }^{19}$ & 2010 & valve & $36 / 36$ & $\begin{array}{l}26.3(28-38) / 23.1 \\
(28-35)\end{array}$ & $17(53.1 \%)$ & $17(47.2 \%)$ & $0 / 8-12$ & $\begin{array}{l}\text { Mortality, Ml, } \\
\text { Reintubation, } \\
\text { Arrhythmia }\end{array}$ \\
\hline Reis $^{29}$ & 2002 & CABG & $76 / 188$ & $63(10) / 62(9)$ & $62(81.6 \%)$ & $150(79.8 \%)$ & $6.9(2.3) / 7.5(7.5)$ & $\begin{array}{l}\text { Hospital stay, Mortality, } \\
\text { MI, Reintubation, } \\
\text { Arrhythmia }\end{array}$ \\
\hline
\end{tabular}

Note: I: Intervention group; C: Control group; CABG: Coronary artery bypass grafting; AVR: Aortic valve replacement; MI: Myocardial infarction; ICU: Intensive care unit; NA: Not available; M: Male; F: Female; N/n: number.

Table 2 Risk of bias 


\begin{tabular}{|c|c|c|c|c|c|c|}
\hline Study & $\begin{array}{l}\text { Random sequence } \\
\text { generation (Selection } \\
\text { bias) }\end{array}$ & $\begin{array}{l}\text { Allocation } \\
\text { concealment } \\
\text { (Selection bias) }\end{array}$ & $\begin{array}{l}\text { Blinding (Performance } \\
\text { bias and detection bias) }\end{array}$ & $\begin{array}{l}\text { Selective reporting } \\
\text { (Reporting bias) }\end{array}$ & $\begin{array}{l}\text { Incoplete outcome } \\
\text { data(Attrition bias) }\end{array}$ & $\begin{array}{l}\text { Other } \\
\text { bias }\end{array}$ \\
\hline Berry $^{7}$ & $?$ & $?$ & + & + & + & + \\
\hline Cheng $^{5}$ & + & + & + & + & + & + \\
\hline Dumas $^{10}$ & $?$ & $?$ & $?$ & + & + & - \\
\hline Michalopoulos ${ }^{8}$ & $?$ & $?$ & + & $?$ & + & + \\
\hline Nicholson ${ }^{17}$ & $?$ & $?$ & + & + & + & + \\
\hline Nougarede $^{18}$ & $?$ & $?$ & $?$ & + & + & + \\
\hline Pettersson ${ }^{26}$ & $?$ & + & $?$ & + & + & + \\
\hline Quasha $^{9}$ & $?$ & $?$ & + & - & + & + \\
\hline Salah $^{27}$ & + & + & $?$ & + & + & - \\
\hline Silbert ${ }^{20}$ & + & $?$ & - & + & - & + \\
\hline Simeone ${ }^{28}$ & $?$ & $?$ & $?$ & + & + & + \\
\hline Reyes $^{30}$ & + & $?$ & + & + & + & + \\
\hline Gangopadhyay ${ }^{19}$ & $?$ & $?$ & $?$ & + & + & $?$ \\
\hline Reis $^{29}$ & $?$ & $?$ & + & + & + & $?$ \\
\hline
\end{tabular}

Table 3 Subgroup analysis of all outcomes based on different extubation time

\begin{tabular}{|c|c|c|c|c|c|c|c|c|c|c|c|c|}
\hline \multirow[t]{2}{*}{ Outcomes } & \multicolumn{4}{|l|}{ ALL } & \multicolumn{4}{|c|}{ Within 4 hours } & \multicolumn{4}{|c|}{ After 4 hours } \\
\hline & MD/RR & $95 \% \mathrm{Cl}$ & $\mathrm{P}^{2}$ & $P^{*}$ & MD/RR & $95 \% \mathrm{Cl}$ & $\mathrm{I}^{2}$ & $\mathrm{P}^{*}$ & MD/RR & $95 \% \mathrm{Cl}$ & $1^{2}$ & $\mathrm{P}^{*}$ \\
\hline \multicolumn{13}{|l|}{ Primary Outcomes } \\
\hline ICU stay (hours) & -9.9 & {$[-15.29,-4.51]$} & $74 \%$ & $<0.01$ & -17.7 & {$[-35.26,-0.15]$} & $86 \%$ & $<0.01$ & -6.01 & {$[-10.60,-1.43]$} & $55 \%$ & 0.09 \\
\hline Hospital stay (days) & -0.63 & {$[-1.22,-0.05]$} & $65 \%$ & $<0.01$ & -0.15 & {$[-0.58,0.27]$} & $0 \%$ & 0.49 & -1.11 & {$[-1.38,-0.83]$} & $0 \%$ & 0.87 \\
\hline \multicolumn{13}{|l|}{ Secondary Outcomes } \\
\hline Death in 30 days & 0.68 & {$[0.10,4.51]$} & $50 \%$ & 0.16 & NA & NA & NA & NA & 0.68 & {$[0.10,4.51]$} & $50 \%$ & 0.16 \\
\hline Death in hospital & 0 & {$[0.02,1.65]$} & $0 \%$ & 0.99 & 0.2 & {$[0.01,4.08]$} & NA & NA & 0.19 & {$[0.01,3.90]$} & NA & NA \\
\hline Death & 0.84 & {$[0.47,1.49]$} & $33 \%$ & 0.22 & 0.42 & {$[0.06,2.77]$} & $0 \%$ & 0.42 & 0.48 & {$[0.04,6.00]$} & $69 \%$ & 0.07 \\
\hline Reintubation & 2.48 & {$[1.09,5.65]$} & $0 \%$ & 0.93 & 1.63 & {$[0.53,4.94]$} & $0 \%$ & 0.85 & 3.9 & {$[1.09,13.92]$} & $0 \%$ & 0.97 \\
\hline Myocardial infarction & 0.36 & {$[0.18,0.72]$} & $18 \%$ & 0.3 & 0.27 & {$[0.11,0.68]$} & $0 \%$ & 0.4 & 0.48 & {$[0.06,3.95]$} & $50 \%$ & 0.16 \\
\hline Bleeding & 1.19 & {$[0.85,1.68]$} & $12 \%$ & 0.33 & 1.73 & {$[0.43,6.91]$} & $51 \%$ & 0.08 & 0.53 & {$[0.17,1.63]$} & $0 \%$ & 0.95 \\
\hline Stroke & 0.36 & {$[0.09,1.47]$} & $0 \%$ & 0.79 & 0.37 & {$[0.02,8.52]$} & NA & NA & 0.36 & {$[0.08,1.72]$} & $0 \%$ & 0.59 \\
\hline Acute renal failure & 1.08 & {$[0.25,4.72]$} & $0 \%$ & 0.74 & 2 & {$[0.19,20.72]$} & NA & NA & 0.68 & {$[0.09,5.14]$} & $0 \%$ & 0.67 \\
\hline Arrhythmia & 1.26 & {$[0.93,1.70]$} & $26 \%$ & 0.25 & 0.66 & {$[0.22,1.97]$} & $87 \%$ & $<0.01$ & 1.61 & {$[1.01,2.57]$} & $35 \%$ & 0.21 \\
\hline
\end{tabular}

Note: $\mathrm{P}^{*}$ : P value for $\mathrm{I}^{2}$, MD: Mean difference; RR: Relative risk; $95 \% \mathrm{Cl}$ : 95\%Confidence interval; NA: Not available; ICU: Intensive care unit.

Table 4 Subgroup analysis of all outcomes based on different cardiac surgery types 


\begin{tabular}{|c|c|c|c|c|c|c|c|c|c|c|c|c|c|c|c|c|c|}
\hline \multirow[t]{3}{*}{ Outcomes } & \multicolumn{4}{|l|}{ ALL } & \multicolumn{4}{|l|}{ CABG } & \multicolumn{4}{|c|}{ Valve } & \multicolumn{4}{|c|}{ CABG/valve } & \multirow{3}{*}{$\begin{array}{l}\mathrm{C} / \\
\mathrm{M} \\
/ \mathrm{R}\end{array}$} \\
\hline & MD & $95 \% \mathrm{Cl}$ & $\left.\right|^{2}$ & $\mathbf{P}^{*}$ & MD & $95 \% \mathrm{Cl}$ & $\mathbf{I}^{2}$ & $P^{*}$ & MD & $95 \% \mathrm{Cl}$ & $\left.\right|^{2}$ & $P^{*}$ & MD & $95 \% \mathrm{Cl}$ & $\left.\right|^{2}$ & $\mathbf{P}^{*}$ & \\
\hline & /RR & & & & /RR & & & & /RR & & & & /RR & & & & \\
\hline \multicolumn{18}{|c|}{ Primary Outcomes } \\
\hline $\begin{array}{l}\text { ICU stay } \\
\text { (Hours) }\end{array}$ & -9.90 & $\begin{array}{l}{[-15.29} \\
-4.51]\end{array}$ & $74 \%$ & $<0.01$ & -5.53 & $\begin{array}{l}{[-9.80} \\
-1.26]\end{array}$ & $60 \%$ & 0.08 & NA & NA & NA & NA & -19.51 & $\begin{array}{l}{[36.57,} \\
-2.45]\end{array}$ & $79 \%$ & $<0.01$ & $\mathrm{~N} /$ \\
\hline $\begin{array}{l}\text { Hospital } \\
\text { stay (Days) }\end{array}$ & -0.63 & $\begin{array}{l}{[-1.22,} \\
-0.05]\end{array}$ & $65 \%$ & $<0.01$ & -0.58 & $\begin{array}{l}{[-1.22} \\
0.07]\end{array}$ & $71 \%$ & $<0.01$ & NA & NA & NA & NA & NA & NA & NA & NA & -1. \\
\hline \multicolumn{18}{|c|}{ Secondary outcomes } \\
\hline Death & 0.84 & $\begin{array}{l}\text { [0.47, } \\
1.49]\end{array}$ & $33 \%$ & 0.22 & 0.22 & $\begin{array}{l}{[0.05} \\
1.00]\end{array}$ & $0 \%$ & 0.46 & NA & NA & NA & NA & 1.21 & $\begin{array}{l}{[0.63,} \\
2.34]\end{array}$ & NA & NA & $\mathrm{N} /$ \\
\hline Reintubation & 2.48 & $\begin{array}{l}{[1.09} \\
5.65]\end{array}$ & $0 \%$ & 0.93 & 2.86 & $\begin{array}{l}{[0.62,} \\
13.10]\end{array}$ & $0 \%$ & 1.00 & 1.00 & $\begin{array}{l}{[0.22,} \\
4.63]\end{array}$ & NA & NA & 4.10 & $\begin{array}{l}{[1.02,} \\
16.46]\end{array}$ & $0 \%$ & 0.85 & $\mathrm{~N} /$ \\
\hline $\begin{array}{l}\text { Myocardial } \\
\text { infarction }\end{array}$ & 0.36 & $\begin{array}{l}{[0.18,} \\
0.72]\end{array}$ & $18 \%$ & 0.30 & 0.35 & $\begin{array}{l}{[0.11,} \\
1.12]\end{array}$ & $0 \%$ & 0.52 & NA & NA & NA & NA & 0.40 & $\begin{array}{l}{[0.06} \\
2.53]\end{array}$ & $74 \%$ & 0.05 & $\mathrm{~N} /$ \\
\hline Bleeding & 1.19 & $\begin{array}{l}\text { [0.85, } \\
1.68]\end{array}$ & $12 \%$ & 0.33 & 0.8 & $\begin{array}{l}{[0.32,} \\
1.99]\end{array}$ & $0 \%$ & 0.75 & 1.03 & $\begin{array}{l}{[0.74} \\
1.43]\end{array}$ & NA & NA & 2.74 & $\begin{array}{l}\text { [0.05, } \\
152.22]\end{array}$ & $73 \%$ & 0.06 & $\mathrm{~N} /$ \\
\hline Stroke & 0.36 & $\begin{array}{l}{[0.09} \\
1.47]\end{array}$ & $0 \%$ & 0.79 & 0.26 & $\begin{array}{l}{[0.03,} \\
2.26]\end{array}$ & $0 \%$ & 0.78 & NA & NA & NA & NA & 0.48 & $\begin{array}{l}{[0.08,} \\
3.11]\end{array}$ & $0 \%$ & 0.38 & $\mathrm{~N} /$ \\
\hline $\begin{array}{l}\text { Acute renal } \\
\text { failure }\end{array}$ & 1.08 & $\begin{array}{l}{[0.25} \\
4.72]\end{array}$ & $0 \%$ & 0.74 & NA & NA & NA & NA & NA & NA & NA & NA & 1.08 & $\begin{array}{l}{[0.25,} \\
4.72]\end{array}$ & $0 \%$ & 0.74 & $\mathrm{~N} /$ \\
\hline Arrhythmia & 1.26 & $\begin{array}{l}{[0.93} \\
1.70]\end{array}$ & $26 \%$ & 0.25 & 0.96 & $\begin{array}{l}{[0.63,} \\
1.46]\end{array}$ & $0 \%$ & 0.90 & 1.17 & $\begin{array}{l}{[0.63} \\
2.16]\end{array}$ & NA & NA & 2.30 & $\begin{array}{l}{[1.23,} \\
4.33]\end{array}$ & NA & NA & $\mathrm{N} /$ \\
\hline
\end{tabular}

Note: $\mathrm{P}^{*}$ : P value for $\mathrm{I}^{2}$; MD: Mean difference; RR: Relative risk; Cl: Confidence interval; NA: Not available; ICU: Intensive care unit; CABG: Coronary artery bypass grafting; AVR: Aortic valve replacement.

Table 5 Subgroup analysis of all outcomes based on different extubation time criteria

\begin{tabular}{|c|c|c|c|c|c|c|c|c|c|c|c|c|}
\hline \multirow[t]{2}{*}{ Outcomes } & \multicolumn{4}{|c|}{ Within 8 hours } & \multicolumn{4}{|c|}{ Within 6 hours } & \multicolumn{4}{|c|}{ Within 4 hours } \\
\hline & MD/RR & $95 \% \mathrm{Cl}$ & $\left.\right|^{2}$ & $\mathbf{P}$ & MD/RR & $95 \% \mathrm{Cl}$ & $\left.\right|^{2}$ & $P$ value & MD/RR & $95 \% \mathrm{Cl}$ & $p^{2}$ & $\mathbf{P}$ \\
\hline \multicolumn{13}{|l|}{ Primary Outcomes } \\
\hline ICU stay $(\mathrm{H})$ & -7.00 & {$[-7.41,-6.59]$} & $0 \%$ & $<0.01$ & -3.74 & {$[-7.49,0.01]$} & $0 \%$ & 0.06 & NA & NA & NA & NA \\
\hline Hospital stay(D) & -0.57 & {$[-1.65,0.51]$} & $93 \%$ & 0.30 & -1.2 & {$[-2.38,-0.02]$} & NA & 0.04 & -0.87 & {$[-2.07,0.32]$} & $0 \%$ & 0.15 \\
\hline \multicolumn{13}{|l|}{ Secondary outcomes } \\
\hline Mortality & 0.32 & {$[0.03,3.05]$} & $0 \%$ & 0.32 & 0.48 & {$[0.04,5.94]$} & $69 \%$ & 0.56 & 1 & {$[0.02,48.80]$} & NA & 1 \\
\hline Reintubation & 2.13 & {$[0.20,22.36]$} & $0 \%$ & 0.53 & 3.2 & {$[0.96,10.66]$} & $0 \%$ & 0.06 & 2.84 & {$[0.12,65.12]$} & NA & 0.51 \\
\hline Myocardial infarction & 0.55 & {$[0.15,1.99]$} & $0 \%$ & 0.36 & 0.49 & {$[0.06,4.10]$} & $51 \%$ & 0.51 & NA & NA & NA & NA \\
\hline Bleeding & 0.87 & {$[0.31,2.44]$} & $0 \%$ & 0.79 & 0.5 & {$[0.05,5.37]$} & NA & 0.57 & 0.94 & {$[0.06,13.93]$} & NA & 0.97 \\
\hline Stroke & 0.65 & {$[0.09,4.81]$} & $0 \%$ & 0.67 & 0.56 & {$[0.11,2.94]$} & $0 \%$ & 0.50 & & & & \\
\hline Acute renal failure & 1.06 & {$[0.29,3.85]$} & $0 \%$ & 1 & 0.42 & {$[0.02,10.11]$} & $0 \%$ & 0.59 & NA & NA & NA & NA \\
\hline Arrhythmia & 0.89 & {$[0.36,2.17]$} & $0 \%$ & 0.80 & 2.03 & {$[1.16,3.56]$} & $0 \%$ & 0.01 & NA & NA & NA & NA \\
\hline
\end{tabular}

Note: P: P value for I²; MD: Mean difference; RR: Relative risk; 95\%Cl: 95\%Confidence interval; NA: Not available; ICU: Intensive care unit; MI: Myocardial infarction.

\section{Figures}




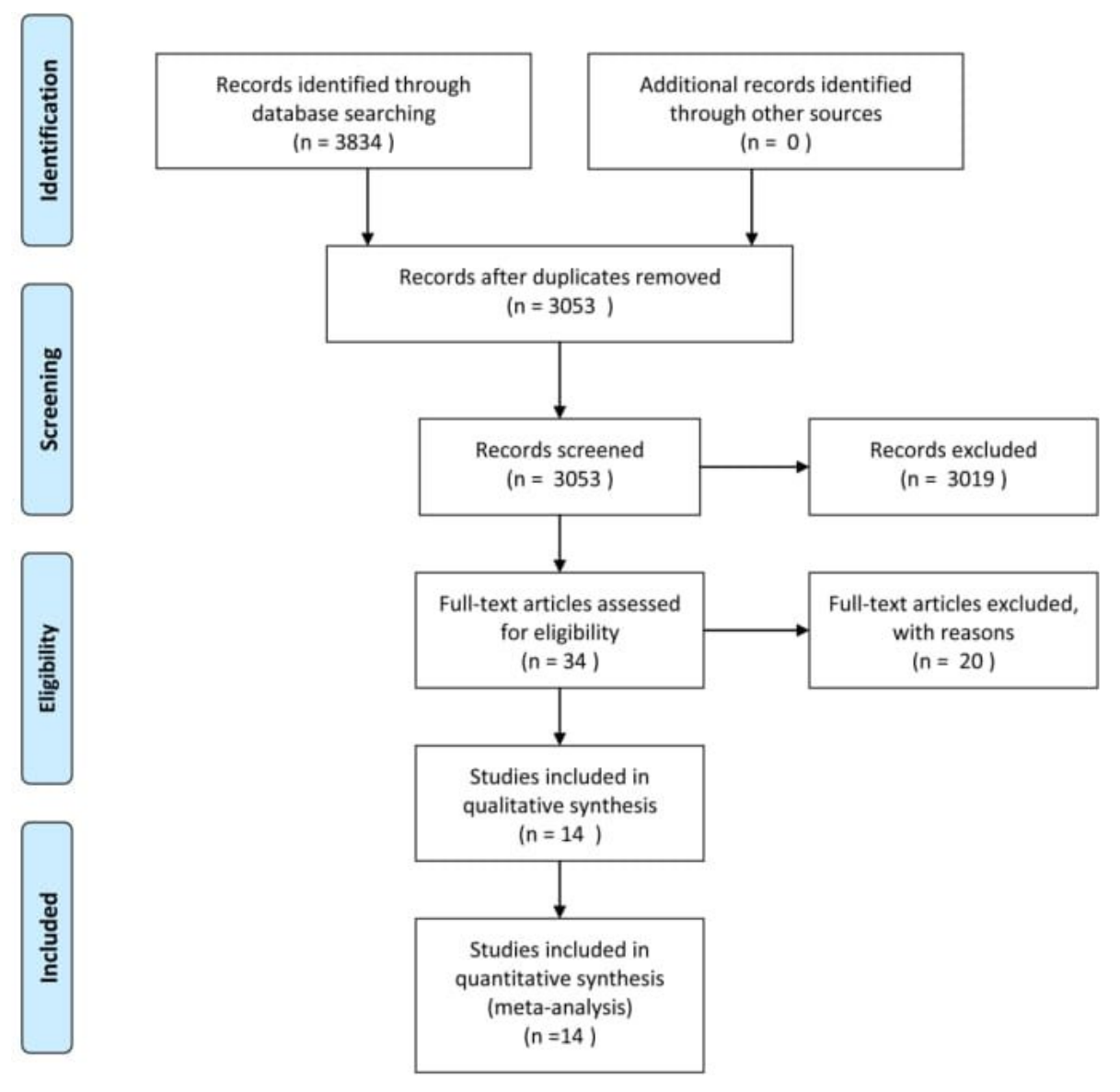

Figure 1

Flow diagram of screening stages

\begin{tabular}{|c|c|c|c|c|c|c|}
\hline \multirow[b]{2}{*}{ Study } & \multicolumn{5}{|c|}{ Experimental } & \multirow[t]{2}{*}{ Contro } \\
\hline & Total & Mean & SD & Total & Mean & \\
\hline Berry 1998 & 43 & 48.00 & 0.0000 & 42 & 48.00 & $12.0 \mathrm{C}$ \\
\hline Nougarede 2004 & 20 & 23.00 & 5.0000 & 20 & 30.00 & 13.00 \\
\hline Quasha 1980 & 16 & 46.00 & 12.0000 & 20 & 57.00 & 29.00 \\
\hline Salah 2015 & 26 & 57.42 & 18.6000 & 26 & 95.04 & 33.58 \\
\hline Cheng 1996 & 51 & 29.20 & 11.7000 & 51 & 30.90 & 12.80 \\
\hline Reyes 1997 & 201 & 27.00 & 190.7500 & 203 & 44.00 & 507.25 \\
\hline Michalopoulos 1998 & 72 & 16.00 & 1.3000 & 72 & 23.00 & 1.20 \\
\hline Simeone 2002 & 24 & 29.00 & 15.8000 & 25 & 46.10 & 33.90 \\
\hline Fixed effect model & 453 & & & 459 & & \\
\hline
\end{tabular}

Random effects model

Heterogeneity: $I^{2}=74 \%, \tau^{2}=26.9066, p<0.01$

trol

SD

Mean Difference

MD

Weight Weight

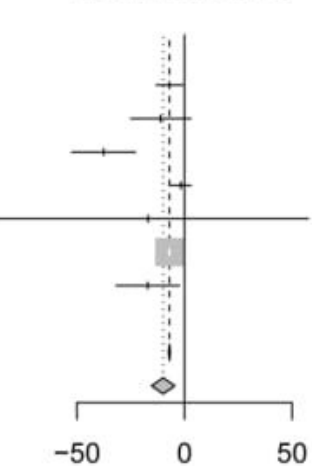

0.00

$-7.00[-13.10 ;-0.90]$

$-11.00 \quad[-25.00 ; 3.00]$

$-37.62[-52.38 ;-22.86]$

$-1.70 \quad[-6.46 ; 3.06]$

$-17.00 \quad[-91.60 ; 57.60]$

$-7.00 \quad[-7.41 ;-6.59]$

$-17.10[-31.82 ;-2.38]$

(fixed) (random)

$-7.00[-7.40 ;-6.59] 100.0 \%$

$-9.90[-15.29 ;-4.51]$

$0.0 \% \quad 0.0 \%$

$0.4 \% \quad 20.6 \%$

$0.1 \% \quad 9.7 \%$

$0.1 \% \quad 9.0 \%$

$0.7 \% \quad 23.0 \%$

$0.0 \% \quad 0.5 \%$

$98.6 \% \quad 28.0 \%$

$0.1 \% \quad 9.1 \%$

\section{Figure 2}

Forest of ICU length of stay 


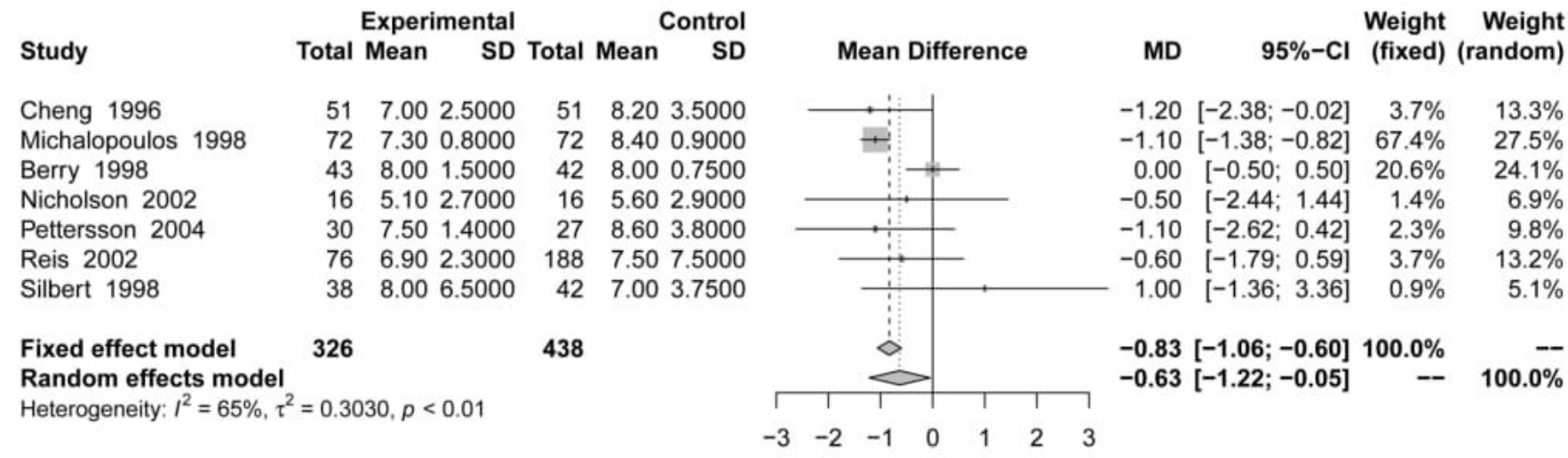

Figure 3

Forest of hospital length of stay

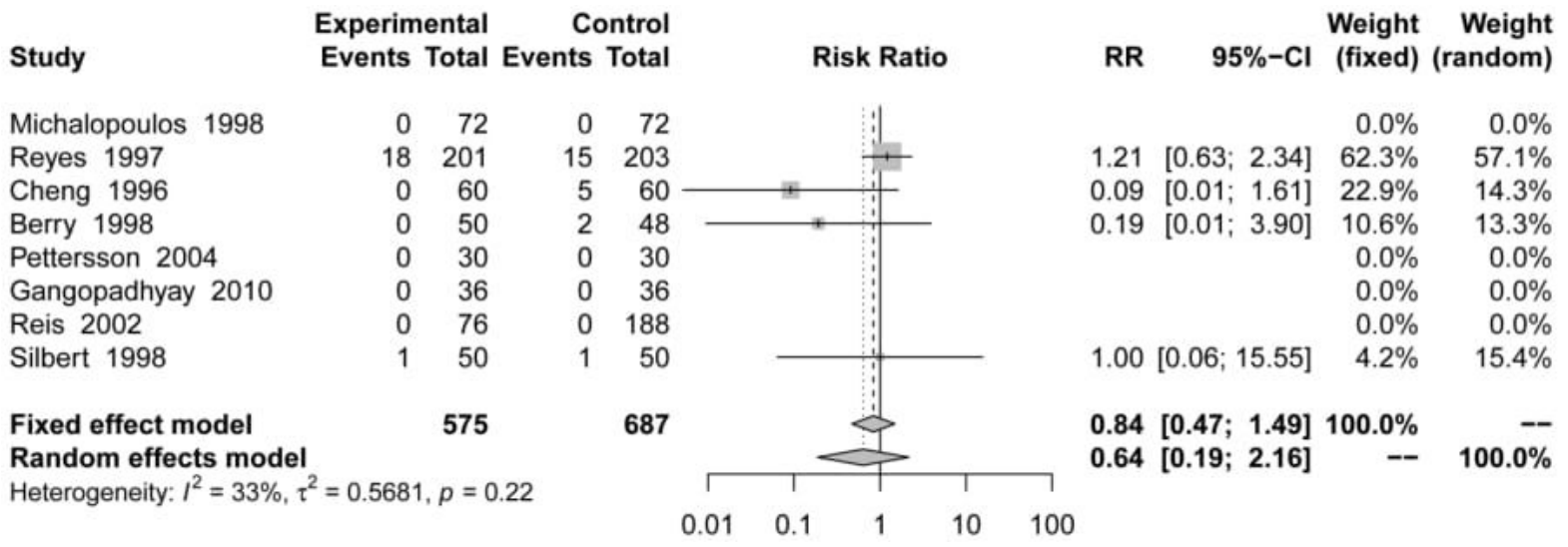

Figure 4

Forest of mortality 